\title{
A compreensão do conceito de momento de uma força: uma proposta para aplicação do cálculo de estruturas para alunos na modalidade PROEJA
}

\author{
Mércio Nascimento Lima1 ${ }^{1}$, Marcello Ferreira ${ }^{2}$ \\ 1,2 Universidade de Brasília (UnB)
}

Palavras-Chave: Momento de uma força, aprendizagem significativa, PROEJA, UEPS.

\section{Introdução}

Pelo Decreto no 5.478, de 24/05/2005, foi criado o Programa de Integração da Educação Profissional ao Ensino Médio na Modalidade Educação de Jovens e Adultos. No mesmo ano, por meio do Decreto № 5.840, de 13/06/2006, foram ampliadas a abrangência e aprofundados seus princípios pedagógicos, passando a se chamar Programa Nacional de Integração da Educação Profissional com a Educação Básica na Modalidade de Educação de Jovens e Adultos - PROEJA (BRASIL, 2005; 2006). No Instituto Federal de Brasília - IFB, criado em 2008, a implementação do PROEJA em alguns campi se deu alguns anos depois, considerando a preparação dos planos de cursos e as necessidades de cada região.

Apesar de ser uma modalidade recente em educação, o PROEJA já apontava algumas dificuldades, entre elas, na sua própria criação, o caráter obrigatório de sua implementação. Isto gerou resistência por parte da comunidade docente, que alegava não ser capacitada para atender este público, além da carência de docente para ministrar algumas disciplinas de formação profissional (FRANZOI et al., 2010). Por outro lado, encontram-se problemas como o da evasão e as dificuldades já encontradas tipicamente na EJA, tais como problemas de pré-requisitos dos alunos, fragilidade ou inexistência de alfabetização científica, muito tempo afastados de sistemas formais de ensino, entre outros, tal como evidenciado por Krueger e Leite (2010).

Considerando as dificuldades apontados anteriormente, no IFB Campus Samambaia foram identificados os mesmos problemas pelos professores do curso técnico em edificações na modalidade PROEJA. No que diz respeito à disciplina Sistemas Estruturais I, isto ficou evidente no cálculo de estruturas. Os professores com formação técnica questionam a falta de pré-requisitos em física, principalmente sobre o tópico momento de uma força, considerado importante para a área de edificações. Essa constatação tornou-se um problema de pesquisa e o norteador para a proposição de uma sequência didática, fundamentada na aprendizagem significativa de Ausubel, que pudesse auxiliar na ministração desse conteúdo em perspectiva aplicada.

\section{Objetivos gerais}

Analisar a percepção do entendimento do conceito de força e torque dos alunos na modalidade PROEJA de um curso de edificações, visando elaborar uma proposta de aplicação desses conceitos no cálculo de estruturas na perspectiva da teoria de aprendizagem significativa de David Ausubel por meio da proposição de uma sequência didática apropriada. Especificamente, (a) investigar os subsunçores relativos à compreensão dos conceitos de força e momento de uma força, em alunos do curso técnico de edificações do PROEJA, para então propor abordagens didáticas que os considerem; (b) desenvolver, aplicar e avaliar uma proposta educacional de ensino aplicada aos alunos do PROEJA, caracterizada por uma Unidade de Ensino Potencialmente Significativa, disponibilizando-a a professores do curso técnico em edificações de ensino médio; e (c) analisar qualitativamente indícios de aprendizagem significativa na resolução de exercícios de cálculo estrutural, com aplicação do conceito de torque.

\section{Metodologia}

Elaborar uma Unidade de Ensino Potencialmente Significativa - UEPS (MOREIRA, 2011) como apoio a professores que trabalham com público PROEJA no curso de técnico em edificações. Para construção da UEPS, serão utilizados textos introdutórios, experimentos simples com materiais de baixo custo, aulas expositivas, simulações, problemas aplicados e vídeos.

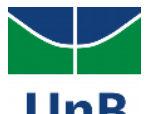




\section{Proposta de aplicação didática}

Aplicação nas turmas iniciais no curso de técnico de edificações PROEJA, tendo como público-alvo alunos na faixa etária de 18 a 60 anos. São previstos quatro encontros para aplicação da UEPS, cada qual com duração de duas horas-aula. As atividades delineadas são as seguintes: 10 encontro: Propor um texto, em nível introdutório, para instigar questionamentos relativos ao conceito de torque e, por situações problemas, investigar a percepção dos alunos, promovendo um debate relativo a este conceito. Estas situações podem funcionar como organizadores prévios. Deste debate, avaliar as estruturas de conhecimento do aluno e o significado que é por ele adquirido a partir da sua relação com seu conhecimento prévio. Após colhidas as informações, separar a sala em grupos para construir, de maneira experimental, com régua milimetradas e pequenos "pesos", modelos simples da relação da distância do ponto de apoio e o ponto de aplicação da força. Após, para cada grupo, a partir de suas observações, será solicitado que proponha uma relação matemática que represente a situação modelo, tomando como avaliação formativa.

20 encontro: Propor que os alunos façam individualmente simulações no PheT (Physics Education Technology - site de simulações interativas da Universidade do Colorado) ${ }^{1}$. Serão propostas três interações (introdução, laboratório de equilíbrio e jogo), com acesso no link movimento/balançando, que descrevem situações de demonstram equilíbrio e giro. Cada aluno deverá anotar percepções em nível introdutório. Após, ainda no PheT, atividade do laboratório de equilíbrio, aumentando gradativamente o nível de compreensão; por fim, será realizado o jogo, com simulações que envolvem seis níveis de dificuldades gradativos e servirá como avaliação individual de cada aluno. 3ำ encontro: Revisão do que foi apresentado com demonstração de vídeos de simulações e situações do cotidiano envolvendo o conceito de momento e torque. Após esta etapa, será realizada aula expositiva, ancorada em subsunçores gerados pelos debates anteriores. Serão apresentados e discutidas situações-problema, para discussão em grupo, envolvendo o tema torque.

4 encontro: Aplicação do conceito de momento no cálculo de estruturas, iniciando com problemas aplicados discutidos em grupo. Abordagem dos problemas com os componentes de cada grupo, para intervenção e discussões complementares que forem necessárias. Aplicação de avaliação.

\section{Resultados esperados}

Após a aplicação da UEPS, espera-se que os alunos participantes do projeto compreendam e formulem proposições satisfatórias (significativas) para problemas que envolvam momento de uma força e cálculo estruturais simples, contrapondo-se a soluções mecânicas (memorizações/aplicação de fórmulas), demostrando capacidade de ressignificação e recontextualização dos conceitos físicos estudados.

\section{Referências}

\section{BRASIL. Ministério da Educação. Programa de Integração da Educação Profissional ao} Ensino Médio na Modalidade de Educação de Jovens e Adultos. Decreto № 5.478: Brasília, 2005.

Brasil. Ministério da Educação. Programa de Integração da Educação Profissional ao Ensino Médio na Modalidade de Educação de Jovens e Adultos. Decreto № 5.840: Brasília, 2006. FRANZOI, N. L. et al. Escola, Saberes e Trabalho: a pesquisa do PROEJA no Rio Grande do Sul. Educação \& Realidade, v. 35, n. 1, p. 168-179, 2010.

KRUGER, J. G.; LEITE, S. Q. M. O ensino de química no curso técnico integrado PROEJA em metalurgia e materiais (IFES campus Vitória): análise das percepções discentes. Ciências \& Cognição, v. 15, n. 1, p. 171-186, 2010.

MOREIRA, M. A. Unidades de Enseñanza Potencialmente Significativas. Aprendizagem Significativa em Revista, v. 1, n. 43. 2011.

\footnotetext{
${ }^{1}$ https://phet.colorado.edu/pt_BR/simulations/category/physics
} 